\section{A Cidade como personagem: Considerações sobre o teatro de rua dos Grupos Revolucena e Dia a Dia}

Narciso Telles

Universidade Federal de Uberlândia

À memória dos saltimbancos João Siqueira e Luiz Mendonça

Durante os anos de 1990 a 1994 participei ativamente na organização dos Encontros de Teatro de Rua de Angra dos Reis- litoral sul do Estado do Rio de Janeiro - onde reúnem-se durante uma semana diversos grupos de teatro e pesquisadores para apresentações e debates sobre a prática do teatro de rua em nosso País.

Dos grupos que assisti, gostaria de destacar os que se dedicam a um circuito alternativo - periferia dos grandes centros e cidades do interior - e, carregam em seus espetáculos temáticas referentes às comunidades onde trabalham, são eles: "Guarda a chave no Trombone" de Parati, "Revolucena" e "Cutucurim" de Angra dos Reis, "Creche na Coxia" de Cabo Frio e "Dia a Dia" do Rio de Janeiro.

No presente estudo procuro analisar as encenações de dois desses grupos "Chora o rio, o rio chora" e "Help, please! A fantasia não desgruda", respectivamente, Revolucena e $\mathrm{Dia}$ a Dia, verificando como estas se constituem enquanto linguagens de teatro de rua, onde a cidade se constitui um elemento presente na construção cênica.

$\mathrm{O}$ teatro de rua ainda é um tema pouco discutido pelos pesquisadores brasileiros. $\mathrm{O}$ status de marginalidade que este modelo teatral adquiriu ao longo da história do teatro ocidental, faz com que nossa historiografia teatral se cale frente às produções teatrais brasileiras que optaram pela rua como espaço de realização de seus espetáculos. Para o fim deste silêncio, também queremos contribuir.

\section{“Acorda, pra discordar!": O Grupo Dia a Dia}

Fundado em 1976 por um grupo de estudantes da UFF, o Grupo Dia a Dia inicia suas atividades com o objetivo de manter vivo o teatro de raízes populares, inserindo nos espetáculos uma visão crítica frente ao contexto social.

Tendo na liderança do grupo o dramaturgo e encenador João Siqueira, - Dia a Dia se torna um expoente do movimento teatral independente na cidade do Rio de Janeiro nos fins dos anos 70 e inicio dos 80, como pontuou o Grupo em seu manifesto "a prática do Grupo é herdeira de uma postura de se fazer "teatro político", via Arena/CPC.

Do Teatro de Arena, podemos perceber a intenção de trazer para a cena os excluídos da sociedade: o operário, o desempregado, a diarista, entre tantos outros. Mas a forma que o Grupo opta é a mais aguerrida, se filiando muito mais a uma influência cepecista. Basta lembrar a ligação de João Siqueira com o CPC no Paraná. ${ }^{2}$

No manifesto escrito em 1981, ano que o Grupo amplia suas atividades voltadas para o teatro de rua, tem a intenção de reavaliar o sentido da sua prática teatral, vinculada a um "teatro político" e, valorizando a independência estética dos grupos. Afirmam: "cada grupo tem seu processo e mesmo trilhando concep̧̧ões estéticas às mais diferenciadas, estarão tendo postura política em relação à sociedade."

Ao perceber as possibilidades e variações estéticas do dito "teatro político", o Dia a Dia, consegue apontar para um caminho semelhante aos grupos independentes paulistas ${ }^{4}$, . valorizando a produção de um teatro popular de criação coletiva, a ser apresentado fora o âmbito comercial, buscando na periferia da cidade do Rio de Janeiro um público que púdesse com ele, estabelecer uma relação crítica frente à realidade.

Em 1994 o Grupo apresenta no Encontro de Teatro de Rua de Angra dos Reis, o espetáculo "Help, please! A fantasia não desgruda" de João Siqueira. O espetáculo é uma releitura de outra encenação do Grupo "Os Filhos de Mamãe Grande". O grupo o define como "grande liturgia dionisfaca, que funde a pompa e o prestígio da corte de papai-grande,

'Manifesto "O Colonialismo do chamado Teatro Político", Grupo Dia a Dia, outubro de 1981. mimeo

'Para verificar a atuaçăo de João Siqueira junto ao CPC, ver BARCELLOS,J. CPC da UNE: Uma história de paixão e consciência. RJ:FUNARTE/Nova Fronteira,1994. pág. 273-282

'Manifesto. Op.cit.

'Silvana Garcia ao estudar os grupos independentes de São Paulo define alguns aspectos recorrentes nestes que são também verificados na trajetória do Dia a Dia. Ver: GARCIA, S. Op. Cit. pág. 124. 
banqueiro de bicho e traficante carioca com a corte dos Borgia."s

Em "Help, please!...", o grupo traz como temática o universo carioca e suas contradições. Mostrando o submundo do carnaval, desfilam pela cena: bicheiros, diaristas com carteira assinada, camelô, marginais, traficantes/mafiosos, e a "putana, carioca, grã-fina". Esta última, mulher do bicheiro Papai Grande, se vê grudada à fantasia de Lucrécia Borgia, vivenciando em determinados momentos do espetáculo esta personagem.

A encenação é construída com o objetivo de contar uma históriaficção. O próprio narrador diz a platéia que "está a fim de teatrar", e começa a se pintar na frente do público, "como manda a etiqueta" e, ao final de sua fala, avisa à todos que na verdade ele é camelô, ali da baixada fluminense.

"Help, please!...", se relaciona como universo da periferia da cidade do Rio de Janeiro - onde está o público preferencial do Grupo através dos personagens-tipo colocados em cena.

Ao utilizar personagens que representam uma generalização, uma determinada categoria social, o Grupo consegue com que a platéia não tenha dificuldade de identificar aquele tipo, presente em seu universo social. Segundo Pavis, "el tipo representa si no un individuo, al menos un grupo bastante restringido de personas." 6

$\mathrm{Na}$ cena, os personagens a todo o momento passam por situações onde há o confronto entre opressores e oprimidos; as músicas, constantes em toda a encenação, cumprem o papel de reforçar a idéia do texto, alertando o público da necessidade de mudanças na ordem política e social do país.

A construção dos personagens-tipo se dá através das informações já contidas no texto e através de laboratórios de observação. É nas ruas da cidade do Rio de Janeiro, em especial dos subúrbios e da baixada, que se encontram os referenciais a serem utilizados pelos atores em seu trabalho.

São estes laboratórios que permitem ao Grupo absorver a "cultura da rua": um modo de falar, um vocabulário e uma gestualidade própria que os atores levam para a cena. Não há preocupação com um trabalho atoral mais técnico, utiliza-se o necessário para a construção do tipo, nada mais.

O público fica no tradicional papel de contemplador do espetáculo. Não há por parte do Grupo nenhuma proposta de alteração desta estrutura. A platéia cabe entender a mensagem, absorvê-la, e aí sim, se quiser, modificar a situação. Mesmo se colocando como um reeleitor do "teatro políti${ }^{5}$ Release do Grupo apresentado à comissăo organizadora do Encontro de Teatro de Rua de Angra dos Reis

${ }^{6}$ PAVIS, P. Dicionário del Teatro.Barcelona:Paidos, 1984. Pág. 514 co" dos anos 60 , a encenação de João Siqueira não avança muito no sentido de propor algo mais do que a mensagem. Toda a proposta transformadora se fixa na dramaturgia e, é ela que promove possibilidades de mudança. “(...) vocês irão se defrontar com uma construção dramatúrgica de personagens que carregam seus próprios contrários. Talvez esse recurso leve a gente a uma reflexão mais dialética e transformadora de nós mesmos e do mundo."

A sobreposição de histórias entremeadas por músicas que ora falam do carnaval carioca, ora da máfia italiana, dá ao espectador a sensação de estar mergulhado no próprio

caos urbano de uma grande metrópole, onde um gigantesco número de informações são jogadas em você a todo o instante. Cria-se em cena uma nova ordenação do mundo, instaura-se a ordem do caos, onde as contradições sociais são colocadas em tensão, objetivando uma melhor apreensão crítica por parte do público. A encenação perde a linearidade da história de papai grande para se sobrepor a ela ,a luta de Lucrécia Borgia pelo poder papal, e seu envolvimento com a máfia italiana e a compra de cocaína.

Esta tensão é também reforçada pelos elementos cenográficos. Nesta montagem são usadas duas escadas colocando os atores num patamar acima da platéia e dos personagens oprimidos, reforçando a diferença de poder e status social entre os personagens personagens.

O teatro de rua, como vemos na encenação do Dia a Dia, não propõe nenhuma interferência no espaço urbano, ao contrário, o Grupo opta pela roda no centro da praça ou da rua, onde o público em volta acòmpanha a história e apreende a mensagem.

A linguagem de teatro de rua do grupo, tem como marca o enfrentamento com a cultura dominante e o teatro comercial.

André Carreira identifica este aspecto transgressor como inerente às produçōes de teatro de rua: "frente a los diversos discursos teatrales dominantes, el teatro callejero ocupa una posición de marginalidad que determina que, para llevar a cabo su tarea, los integrantes de los grupos callejeros deben realizar grandes esfuerzos, tanto en lo que se refiere al mundo espiritual como al mundo material; deben poseer una potente motivación ideológica, la cual los condena a ocupar un lugar de oposición $y$ de enfrentamiento con la cultura que os margina."

A relação da cidade do Rio de Janeiro com as montagens do Dia a

'SIQUEIRA.J. O Teatro de João Siqueira .RJ: ed. do autor, 1984. Pág. 08 
Dia, é pautada pela necessidade que o grupo tem de mostrar as contradições existentes nela, através dos personagens. E é essa postura que determina a linguagem do grupo, e o aspecto marginal de seu teatro.

\section{Grupo Revolucena: quando a cena vira rua}

O Grupo Teatral Revolucena se forma no ano de 1979 por alunos do Colégio Estadual Arthur Vargas (CEAV), sob a direção de Zequinha Miguel. Ao longo dos anos o grupo, não fugindo à regra, passa por modificações no elenco original e, se desvincula do local de formação.

O próprio nome do Grupo já demonstra sua inquietude diante do mundo, uma inquietude que se configurou em seu projeto teatral, como nos diz o ator José Marcos Castilho: "A discussão do Revolucena não passava pelo teatro clássico, nós discutíamos desde o início a importância do teatro como instrumento de conscientização. ""

Tendo como matrizes téricas-estéticas as propostas de Paulo Freire e Augusto Boal $^{10}$, o Revolucena encontrou no teatro de rua o espaço de discussão e denúncia da situação social de seu município.

Foi a possibilidade do teatro como veículo de conscientização para a transformação, que fez o Grupo escolher a rua como espaço cênico.

"Nós decidimos priorizar a rua como espaço cênico em função disso. Era fundamental que a gente fizesse teatro de rua porque era um instrumento importante na luta política." 11

Em 1989, o Grupo apresenta o espetáculo "Chora o rio, o rio cho$r a$ ". Enfocando o problema da poluição do Rio do Choro - rio que passa pelo centro da cidade e que devido ao crescimento urbano foi se transformando em depositário da rede de esgoto - o Grupo mais uma vez parte da denúncia de um fato, o tema para construir seu espetáculo.

Realizado no próprio leito do rio, o espetáculo iniciava-se com os atores, em procissão, trazendo o andor com o "Velho Galixo"12 entoando um cântico de lamento pela degradação do rio. Num determinado ponto, em frente a principal avenida do centro da cidade, a procissão parava

"CARREIRA, André. Delimitacion del Concepto de Teatro Callejero, 1998. (Texto inédito) Pág. 06

'Entrevista de José Marcos Castilho

10 Estas propostas são vinculadas ao teatro e a pedagogia do oprimido, e serăo discutidas com maior profundidade em minha dissertaçăo de mestrado.

"Entrevista de José Marcos Castilho

\section{urdimento 3/2000}

ouvindo-se apenas os cânticos. E, devagar o andor era suspenso até a altura da rua, onde iniciava-se o monólogo do "Velho Galixo", que aparecia com uma roupa cheia de lixo: latas, garrafas, objetos de higiene pessoal. Durante a fala deste personagem questōes da história do rio e a denúncia do atual estado de degradação eram focalizadas. Após o texto o andor era arriado e a procissão ia embora se distanciando aos olhos do público.

Somente o ator de faz o personagem "Galixo" tem um figurino proprio, todos os outros estão vestidos de preto, com tochas na mão - única iluminação da cena - e rostos brancos, caracterizando um cortejo fúnebre. Esta encenação apresenta aspectos interessantes a serem discutidos: primeiramente, a forma que o Grupo se utiliza do espaço urbano.

Diferentemente de trabalhos anteriores do Revolucena, "Chora o rio..." o Grupo utiliza o espaço urbano tal como ele é, ou seja, a cenografia não é construída para um fim teatral, ela é dada pelo próprio traçado urbano da cidade e é o Grupo que a define no momento do espetáculo como um espaço cênico, imbricando-se a ele. Assim, a cena permeia o espaço urbano transformando-o em um determinado momento em espaço teatral, onde a comunhão com o público se faz fundamental.

No dia do espetáculo o Grupo foi de casa em casa, pedindo aos moradores que durante o horário da peça não dessem descarga em seus banheiros, pois se isso ocorresse todo o esgoto iria em cima dos atores.

Um outro aspecto é a participação do público.

O público no espetáculo do Revolucena é um elemento de extrema importância. O próprio processo de construção da cena é pensado cờm a participação dele. Neste, em especial, contribui efetivamente para a realização integral do espetáculo, pois, ao atenderem o pedido dos atores para não usar as descargas sanitárias durante a apresentaçāo, assumem uma outra condição frente ao mesmo: o de co-realizador.

Esta atitude, faz com que a platéia seja realocada de seu estado de passividade, de contemplação ao que é mostrado em cena. Mesmo aqueles que não moram próximo ao local do espetáculo, ao terem que - para observar o cortejo no leito do rio - descobrir uma forma e um local mais adequado para olhar a encenação, passa também, por um momento de interação junto à cidade, descobrindo uma nova forma de se portar no espaço.

Essa possibilidade de rompimento do tradicional formato de ocupação da rua como espaço teatral, que o teatro de rua do Revolucena trás,

1"Galixo era o nome dado ao Rio do Choro no início do séc. XIX 
realocando a relação da encenação com a cidade, faz com que este grupo se dedique apenas em apresentar seus espetáculos no próprio municípiosede. Angra dos Reis é o local onde o teatro do Revolucena ocorre e adquiri força, vitalidade.

Sobre esta questão, gostaria de mencionar algumas palavras de Fernando Peixoto: "o espaço cênico é tudo. E sua escolha ou aceitação determina não apenas aspectos de ordem física, com evidentes conseqüências estéticas mas igualmente aspectos sociais. "13

No Revolucena todo o trabalho de criação dos atores era realizado a partir de inúmeras improvisações. As cenas eram criadas e acrescidas da pesquisa individual dos personagens, já realizadas pelos atores.

Esta disponibilidade de escolha do personagem pelo ator $\mathrm{e}$ a liberdade de criação passava por uma ética presente entre os próprios membros do Grupo. $\mathrm{O}$ ator era livre, mas dentro de regras, ou seja, toda a criação era debatida, antes de ser colocada efetivamente no espetáculo.

"No processo de criação com muita gente, comȩ̧ou a surgir várias idéias, cada um começou a optar pelo seu próprio personagem, entendeu, nosso processo sempre foi das pessoas escolherem e criarem seus próprios personagens. 14

Todo o trabalho de criação dos atores era realizado a partir de inúmeras improvisaçōes.

São as improvisações contínuas que marcam a forma de treinamento dos atores. Ao acreditar que a espontaneidade possa ser um dos elementos fundamentais para o ator, o Revolucena, mesmo sem assumir diretamente, utiliza-se de elementos presentes no método de Stanislavski da "análise ativa". É da própria improvisação que os diálogos são criados. Disto, estabelece-se uma organicidade maior entre a interpretação e o texto, pois os dois nascem de um mesmo processo.

Para os atores-revolucenas o treinamento do ator passa por uma disponibilidade para a cena, objetivando adquirir uma vivência maior do personagem:

"Eu sempre senti que o personagem do teatro de rua é parte do momento da cena, é diferente do palco. Você naquele momento está sendo o próprio personagem"15.

Assim, os personagens são construídos com as informações (formas de andar, falar, gesticular, etc) pesquisadas pelos atores nas ruas, e

I'PEIXOTO, Fernando. Espaço Cênico, qualquer espaço Revista da POIESIS, s/d.

${ }^{14}$ Entrevista de Marcelo Germano daí, passam por um processo de reelaboração através das improvisações nas circunstâncias da cena. Sobre esta questão o ator Marcelo Germano afirma: " a gente mistura o ator, o personagem e alguém que a gente viu na rua."

A pesquisa individual do ator, conforme podemos perceber, ultrapassa o campo específico da interpretação, e, ocupa espaços maiores de construção da cena, como a criação do próprio figurino.

A cidade, também, é enfocada pela dramaturgia do espetáculo. Composto apenas pelo monólogo do Velho Galixo, o texto se propõem uma revisão do passado como elemento de reflexão do presente.

Ao narrar sua história, o Velho Galixo descreve o processo histórico da cidade e a relação desta com o rio, chegando ao atual estado de degradação, derivado do próprio crescimento urbano do munić́pio.

O teatro de rua tal como é entendido pelo Revolucena nesta montagem, se baseia em retirar das ruas os elementos de sua proposta estética, e assim, pensar a cena como um território lúdico no espaço urbano da cidade de Angra.

\section{Conclusão}

As encenações de "Help, please! A fantasia não desgruda!", do Grupo Dia a Dia e "Chora o rio o rio chora" do Revolucena, possuem uma intrínseca relação com suas cidades.

A primeira leva a cena o universo carioca, seus conflitos e çontradições, através dos personagens-tipo que promovem uma assimilação imediata da platéia com o espetáculo e, reafirma o aspecto marginal do teatro de rua. Sem buscar possibilidades de interação com o espaço urbano, o grupo se apresenta em roda e o público fica no tradicional papel de contemplador da história. Mesmo tendo assistido o espetáculo fora da cidade-sede do grupo, não verificamos nenhuma possibilidade de alteração nesta estrutura.

A encenação do Revolucena também traz a cidade representada nos personagens, mas também propõe uma relação da cena com a cidade, resignificando o espaço urbano.

Utilizando-se do leito do Rio do Choro, a encenação cobra uma postura social e cênica do público frente à sua degradação, promovendo, assim, a conscientização da platéia sobre a questão e uma interação dela com o espaço.

1'Entrevista de Marcelo Germano 
As linguagens teatrais desses grupos, com suas diferenças e semelhanças, buscam uma relação mais próxima com suas comunidades, levam à cena seus projetos, anseios e visōes sobre a sociedade onde se inserem. O Revolucena e o Dia a Dia, configuram uma identidade própria do fazer teatral, onde a cidade - espaço cênico ou personagens - tem um papel fundamental.

\section{Bibliografia}

CARREIRA, André. 1998. Delimitacion del Concepto de Teatro Callejero, Mimeo.

GARCIA, Silvana. 1990. Teatro da Militância.São Paulo: Perspectiva. GUIMARÃES, Gonçalo. 1997. Uma Cidade para Todos: O Plano Diretor do Município de Angra dos Reis.Rio de Janeiro: Forense.

PEIXOTO, Fernando. s/d. O Espaço Cênico, qualquer espaço. Revista da POIESIS, s/d.

SIQUEIRA, João. 1984. O Teatro de João Siqueira. Rio de Janeiro, Edição do autor. 